\title{
Climate change as a driver of conflict in Afghanistan and other Fragile and Conflict Affected States
}

\author{
Roz Price \\ Institute of Development Studies \\ 18 January 2019
}

\section{Question}

What is the evidence base on climate change as a driver of conflict in Afghanistan and other Fragile and Conflict Affected States (FCAS)?

\section{Contents}
1. Summary
2. Links between conflict and climate change
3. Climate-conflict links in Afghanistan
4. Other FCAS case studies
5. References

The K4D helpdesk service provides brief summaries of current research, evidence, and lessons learned. Helpdesk reports are not rigorous or systematic reviews; they are intended to provide an introduction to the most important evidence related to a research question. They draw on a rapid deskbased review of published literature and consultation with subject specialists. 


\section{Summary}

The report provides a brief account of the current state of knowledge of the links between climate change and conflict. It then presents relevant literature from Afghanistan (although this is limited), and finally examples from other countries or regions where links have been proposed (many of which can be considered fragile and conflict affected states (FCAS)).

A growing number of researchers are linking climate change to violent conflict; however, robust scientific evidence of this relationship remains obscure and contested (for example the link between drought and the Syrian uprising). Although a direct, linear relationship between climate change and conflict is disputed, much of the literature agrees on an indirect link where climaterelated change can influence factors that lead to or exacerbate conflict under certain circumstances. Hence, understanding how and under what circumstances these changes may lead to violent conflict is key. Much of the literature reviewed emphasises that policy responses to climate-related security risks need to acknowledge the complexity of the climate-conflict relationship through specific mechanisms, and to be adapted to specific local contexts. Political, spatial and temporal dimensions should also be included when studying these links.

The primary sources used in this review were papers published in peer reviewed scientific journals and other grey literature. There are a number of recent detailed synthesis of the climateconflict literature which provide more comprehensive reviews of the evidence both for and against such a relationship and discuss knowledge gaps (for example see Adger et al., 2014; Burke et al., 2015; Dell et al., 2014; Gemenne et al., 2014). There are a number of areas where further research is needed. These include the need to analyse the absence of conflict in the face of climate risks, the need to expand the range of issues accounted for in analysis of climate and security including the impacts of mitigation response on domains of security, and the need to include theories of asymmetric power relations in explaining security dimensions (Gemenne et al., 2014).

Literature has been rapidly expanding in this area but geographic coverage is still biased towards certain areas (in particular sub-Saharan Africa and East Africa). As found by Nordqvist and Krampe (2018) there is not enough known about the climate-conflict relationship in Afghanistan (which is critically under researched) and the surrounding South Asia and South East Asia regions. In general, there is a lack of rigorous academic studies that focus on the climate-conflict relationship for these regions as well as other regions such as Latin America. Three other major biases in climate-conflict research have been highlighted in the literature: research primarily focuses on a few accessible regions, ignores the regions/countries most affected by climate change, and overstates the links between climate change and conflict by focusing on the regions that have been conflict-affected (Adams et al., 2018). There is therefore a need for further rigorous research. The literature in this review was largely gender-blind, even though gender plays a crucial role in both conflict, climate change and peacebuilding.

Many findings in this report, whilst context-specific, reflect similar insights into mechanisms through which climate change may affect violent conflict (although it is important to remember the wide-array of other factors that also influence conflict dynamics):

- Rüttinger et al. (2015) identified seven complex climate-fragility risks that emerge when climate change interacts with other social, economic, and environmental pressures: (1) Local resource competition; (2) Livelihood insecurity and migration; (3) Extreme weather events and disasters; (4) Volatile food prices and provision; (5) Transboundary water 
management; (6) Sea-level rise and coastal degradation; (7) Unintended effects of climate policies. These risks are not isolated and interact with each other in complex ways.

- Lukas and Rüttinger (2016) highlight four major climate-fragility risks for Afghanistan: (1) Land degradation and natural resource conflicts; (2) Scarcity and illicit livelihoods; (3) Transboundary water conflicts and armed insurgency; (4) Rapid-onset disasters and instability.

- Nordqvist and Krampe (2018) analysed literature on climate-conflict links in South Asia and South East Asia, and found that existing research addresses similar categories of mechanisms as those presented in previous reviews of other regions (such as the Horn of Africa). They found context-specific evidence that climate change can have an effect on the causes and dynamics of violent conflict in the region when: (a) it leads to a deterioration in people's livelihoods; (b) it influences the tactical considerations of armed groups; (c) elites use it to exploit social vulnerabilities and resources; and (d) it displaces people and increases levels of migration. These mechanisms are often interlinked and more noticeable in some climatic, conflict and socio-economic contexts.

- van Baalen and Mobjörk (2018) explore how climate change affects the risk and dynamics of violent conflict in East Africa. Conflicts around natural resources - land, pasture, water - are particularly frequent where livestock rearing pastoralists are involved. They identify four key mechanisms in East Africa: i) deteriorating livelihoods, ii) increased migration and changes in pastoralist mobility patterns, iii) tactical considerations among armed groups, and iv) elite capture of local disaffection.

- A recent climate-related security risk assessment of Iraq identified the following priority risks (Hassan et al., 2018): (1) Diminished agricultural livelihoods increase local support for terrorist groups; (2) Insufficient governance capacity to address and respond to climate change and environmental degradation; (3) Increased dependence on water flows from riparian neighbours and regional stability; (4) Mass displacement and forced migration; (5) Heightened communal tensions over access to food and water.

\section{Links between conflict and climate change}

\section{Current state of knowledge}

In the past decade, there has been a surge of research into whether there is a robust association between different aspects of climate change and conflict, with evidence both for (Burke et al., 2015) and against (Abrahams and Carr, 2017; Adger et al, 2014; Buhaug, 2015) such a relationship. Although a growing number of researchers are linking climate change to violent conflict, scientific evidence of this relationship remains obscure "due to heterogeneous research designs, variables, data sets and scales of analysis" (Adams et al., 2018, p.200). Buhaug (2015, p.269) argues that a "decade of systematic research on climate change and armed conflict has revealed a number of interesting patterns but few results that are robust across studies". Other authors dispute this. A recent literature review by Sida $(2018$, p.4) on the relationship between climate change and violent conflict summarises the general conclusion that "there is no direct and linear relationship..., but under certain circumstances climate-related change can influence factors that lead to or exacerbate conflict". 
As concluded by Working Group II of the Intergovernmental Panel on Climate Change's (IPCC) $5^{\text {th }}$ Assessment Report (AR5), there is strong evidence that "Human security will be progressively threatened as the climate changes" (Adger et al., 2014, p.758). The AR5 further highlights that "Human insecurity almost never has single causes, but instead emerges from the interaction of multiple factors. [...]Climate change is an important factor threatening human security through (1) undermining livelihoods [...]; (2) compromising culture and identity [...]; (3) increasing migration that people would rather have avoided [...]; and (4) challenging the ability of states to provide the conditions necessary for human security" (Adger et al., 2014, p.758). However, evidence on the effect of climate change on violent conflict and human security is contested, and there is "little agreement about direct causality" (Adger et al., 2014, p.758). explains that "linking structural factors embedded in uncertainty, such as climate change, to rare social outcomes, like violent conflict, is a highly complicated endeavour"

The Sida review highlights that there is "no evidence of interstate conflicts where climate change is a direct or indirect cause. But climate-related effects will grow in magnitude with consequences in space and time that are difficult to predict" (Sida, 2018, p.4). Furthermore, the review summarises how the state of knowledge on this relationship has evolved "during the past ten years, from depicting simple, deterministic causal chains and catastrophic scenarios to a much more nuanced view from the realization that the risk of conflict is highly context dependent, where causality is multifactorial and complex" (Sida, 2018, p.6). Studies (such as Van Baalen and Mobjörk's (2018) review of East African studies) show that there may be "indirect linkages between climate change and the risk of conflict, where factors that play a role in increasing conflict risk may be reinforced by climate change" (Sida, 2018, p.9). It is thus particularly important to "understand how and under what circumstances these changes may lead to violent conflict. Such a context specific approach may give guidance as to what concrete actions contribute to reducing the risk of conflict" (Sida, 2018, p.9).

Abrahams and Carr (2017, p.233) explore the connections between climate change and conflict through a geographic and political ecology literature lens, which they argue:

"uniquely challenges the dominant 'threat multiplier' framing of climate change's impact on climate, questioning this narrative's unidirectional flow from climate vulnerability to conflict, exploring how climate change can create opportunities for peacebuilding as well as conflict, and identifying how climate adaptation activities can themselves become catalysts for conflict".

Abrahams and Carr (2017, p.236) explain that the "threat multiplier" discourse (i.e. that climate change will not cause conflict, but it can exacerbate the risks or worsen the impacts of conflict) was "popularised by a 2007 report by the Center for Naval Analysis (CNA), and has persisted, despite CNA more recently reframing climate change as a conflict catalyst that accelerates instability". They highlight that the "threat multiplier" discourse is relatively vague and unidirectional, and that the climate-conflict relationship is not merely one where climate change drives conflict vulnerability.

Abrahams and Carr (2017, p.239) highlight the following as some of the few "points of consensus in the often-contentious climate-conflict literature":

- The relationship between climate change and conflict is not causal; it is widely acknowledged that climate change interacts with a host of other issues to produce conflict (or build peace). 
- While the places most likely to be affected by climate change-affected conflict have preexisting tensions and are likely to have limited capacity to cope with climatic shifts, focusing heavily on places with a reliance on primary production and limited adaptive capacity overly-constrains our understanding of conflict outcomes.

- Conflict increases vulnerability to climate change.

- Adaptation efforts can trigger conflict.

\section{Drought and conflict}

In particular, drought has been researched heavily in the climate-conflict literature, and may have a more robust link with violence than other climate-related natural disasters, such as flooding. For example, a study by Schleussner et al. (2016) based on data on armed-conflict outbreaks and climate-related natural disasters for the period 1980-2010, found that the link between climate disasters and conflict was particularly strong in ethnically divided countries, and was stronger for droughts and heatwaves than for floods.

von Uexkull et al. (2016, p.12391) presented "an actor-oriented analysis of the drought-conflict relationship, focusing specifically on politically relevant ethnic groups and their sensitivity to growing-season drought under various political and socioeconomic contexts", looking at conflict event data that covers Asia and Africa between 1989-2014. Their analysis reveals that the impact of drought on conflict under most circumstances is limited: "However, for agriculturally dependent groups as well as politically excluded groups in very poor countries, a local drought is found to increase the likelihood of sustained violence" (von Uexkull et al., 2016, p.12391). They interpret this as evidence of the reciprocal relationship between drought and conflict, whereby each phenomenon makes a group more vulnerable to the other. They conclude that their results emphasise "the importance of strengthening adaptive capacities of agriculturally dependent communities, in particular in areas already affected by conflict" (von Uexkull et al., 2016, p.12395).

Couttenier and Soubeyran (2014) explored the relationship between drought and civil war, and found that the link between rainfall, temperature and civil war found in previous literature may be driven by aggregate shocks (such as global climate) that were not accounted for. A standard differences-in-differences specification relying only on within country variation reveals a much weaker and insignificant link between weather variables and civil war. They used the Palmer drought severity index (a meteorological measurement of drought) to explore this link on a local level. However, they found that evidence for a positive link between drought and civil war was weak. They conclude that richer data are needed to obtain firm conclusions regarding the climate-conflict relationship (Couttenier and Soubeyran, 2014, p.213).

\section{Mechanisms for conflict under climate change}

Rüttinger et al. (2015), in an independent report commissioned by the G7 members on climate change and fragility risks, identified seven compound climate-fragility risks that emerge when climate change interacts with other social, economic, and environmental pressures -which they say "pose serious threats to the stability of states and societies in the decades ahead" (Rüttinger et al., 2015, p.vii). They further emphasise that these seven climate-fragility risks are not isolated from each other but interact in complex ways. The seven climate-fragility risks identified are (Rüttinger et al., 2015, pp.viii-x): 
1. Local resource competition: As the pressure on natural resources increases, competition can lead to instability and even violent conflict in the absence of effective dispute resolution.

2. Livelihood insecurity and migration: Climate changes will increase the human insecurity of people who depend on natural resources for their livelihoods, which could push them to migrate or turn to illegal sources of income.

3. Extreme weather events and disasters: Extreme weather events and disasters will exacerbate fragility challenges and can increase people's vulnerability and grievances, especially in conflict-affected situations.

4. Volatile food prices and provision: Climate change is highly likely to disrupt food production in many regions, increasing prices and market volatility, and heightening the risk of protests, rioting, and civil conflict.

5. Transboundary water management: Transboundary waters are frequently a source of tension; as demand grows and climate impacts affect availability and quality, competition over water use will likely increase the pressure on existing governance structures.

6. Sea-level rise and coastal degradation: Rising sea levels will threaten the viability of lowlying areas even before they are submerged, leading to social disruption, displacement, and migration, while disagreements over maritime boundaries and ocean resources may increase.

7. Unintended effects of climate policies: As climate adaptation and mitigation policies are more broadly implemented, the risks of unintended negative effects - particularly in fragile contexts - will also increase.

However, Abrahams and Carr (2017, pp.237-238) underscore that "Nearly all of these compounding factors assume reliance on primary production or limited adaptive capacity", and "ignore larger issues of political economy when explaining the rise (or lack of a rise) of conflict in particular places".

Most climate-conflict research has focused on East Africa and sub-Saharan Africa, and the links remain understudied in South Asia and South East Asia (see Adams et al., 2018). Nordqvist and Krampe (2018, p.1) recently undertook a systematic literature review of climate-conflict research in South Asia and South East Asia and highlight that "Although these regions have been greatly affected by both climate change and conflict, there have only been a small number of rigorous academic studies that focus on the climate-conflict relationship".

Nordqvist and Krampe's analysis finds that existing research addresses similar categories of mechanisms linking climate change to the risk of violent conflict as those presented in previous reviews of other regions. Nonetheless, there were also noticeable differences between the way these mechanisms play out in the two regions of Asia and in other regions of the world (such as the Horn of Africa), which is to be expected given their different climatic, conflict and socioeconomic contexts. For example, conflicts between herders and farmers, which are a key aspect of the links between climate and conflict in East Africa, are not a relevant feature in South Asia and South East Asia (Nordqvist and Krampe, 2018, p.2). The review also "reveals interesting nuances in the types of violence linked to climate change; that is, the type of violence appears to depend on the social and political context, rather than any observable climate-related environmental change" (Nordqvist and Krampe, 2018, p.5). The review highlights that although the scarce evidence base "constrains the ability to draw general conclusions, there is context- 
specific evidence that climate change can have an effect on the causes and dynamics of violent conflict in the region when" (Nordqvist and Krampe, 2018, p.1):

a) it leads to a deterioration in people's livelihoods;

b) it influences the tactical considerations of armed groups in ongoing conflicts;

c) elites use it to exploit social vulnerabilities and resources; and

d) it displaces people and increases levels of migration in vulnerable and highly vulnerable natural resources dependent contexts.

The review also acknowledges that the aforementioned mechanisms are often interlinked and more noticeable in some climatic, conflict and socio-economic contexts than in others; it also agrees with other research that the climate-conflict linkage primarily plays out in contexts that are already vulnerable to climate change, and where income is highly dependent on agriculture and fishing (Nordqvist and Krampe, 2018, p.9). Hence, there is a need for more research in South Asia and South East Asia; in particular, there is a lack of rigorous evidence from Afghanistan, Myanmar and Pakistan, which are experiencing both climate change and violent conflicts. Also, research into comparators of regions that are highly vulnerable to climate change but are able to peacefully mitigate such stressors (Nordqvist and Krampe, 2018, p.9).

\section{Vulnerability and fragile states}

In the review of climate-conflict relationship by Sida (2018) it was found that fragile states and communities with a history of conflict are the most vulnerable to worsened conflict, due to further climate-related stress. Lukas and Rüttinger (2016, p.III) in their German Ministry of Foreign Affairs-funded analyses of the links between climate change and Non-State Armed Groups, also emphasise the complexity of the relationship between climate change, conflict and fragility, and that fragile states are particularly vulnerable:

"The increasing impacts of climate change do not automatically lead to more fragility and conflict. Rather, climate change acts as a threat multiplier. It interacts and converges with other existing risks and pressures in a given context and can increase the likelihood of fragility or violent conflict. States experiencing fragility or conflict are particularly affected, but also seemingly stable states can be overburdened by the combined pressures of climate change, population growth, urbanization, environmental degradation and rising socio-economic inequalities".

Stites and Bushby (2017, p.8) also highlight this connection, adding that "many countries categorised as conflict-affected or fragile states are particularly at risk to the impacts of climate change ([e.g.] Bangladesh, Myanmar, Pakistan and Somalia[..]), with their most vulnerable populations at heightened risk". This is because many poor and marginalised populations in rural areas often rely heavily on natural resources to sustain their livelihoods, which may be negatively impacted by climate change leading to out-migration and competition within these groups (Stites and Bushby, 2017, p.8).

Vivekananda et al. (2014) aimed at better understanding resilience to climate and environmental changes in fragile and conflict-affected societies through a conceptual framework exploring the climate-fragility-conflict and climate-resilience-peace nexus (see Figure 1). They set out a framework which "stresses the need to understand the linked conceptual pairs of fragility and stability, vulnerability and resilience, and human security and insecurity, in order to analyse the pathways between climate change and violent conflict or peace" (Vivekananda et al., 2014, 
p.497). They conclude, "The double dividend of resilience to conflict and climate change can only be achieved if the contextual complexities are taken into account. For the climate change community this means to ensure their adaptation efforts are peace-positive, and for the peacebuilding and development communities it means to ensure their conflict mitigation and development efforts are climate-proof" (Vivekananda et al., 2014, p.497).

Figure 1. Integrated framework of the climate change-conflict/peace nexus

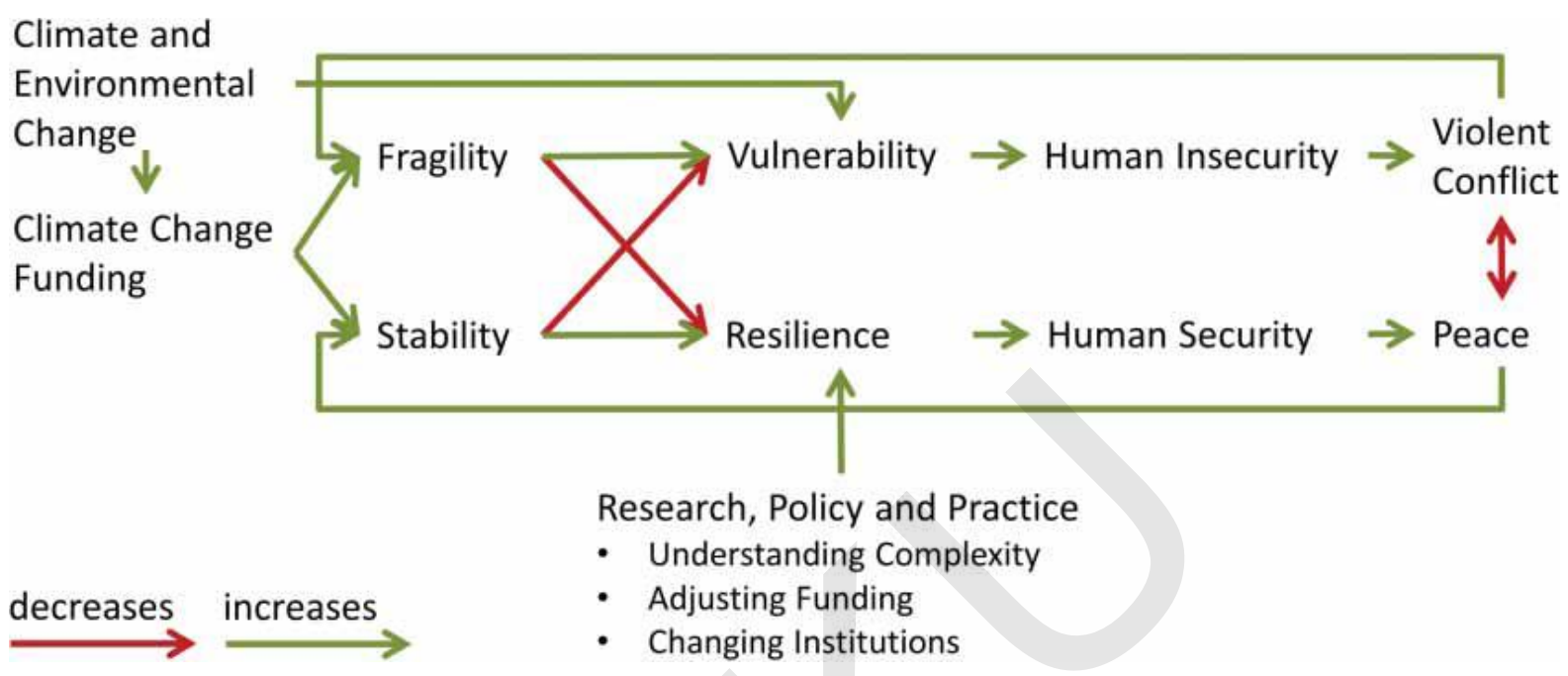

Source: Adapted from Vivekananda et al. (2014, pp.493)

\section{Biases in climate-conflict studies}

A number of studies have recently highlighted the tendency for climate-conflict research to be concentrated in certain regions, leading to significant biases (see Adams et al., 2018). Hendrix (2018, p.190) highlights that this "may limit understanding of the socioeconomic and political conditions in which such conflict occurs, and how these conflicts could be prevented".

Adams et al. (2018) explored whether the research claiming a link between climate change and violent conflict is based on a biased sampling strategy through a systematic review of the relevant academic literature for the period 1990-2017. They highlight three major biases in climate-conflict research (Adams et al., 2018, also reflected in Hendrix, 2018):

- Scholars have "gone looking for climate-conflict links in countries and regions that have been conflict-affected, rather than those most affected by climate change", ignoring locations where environmental shocks were not followed by armed conflict. For example, "the drought that affected Syria also affected neighbouring Jordan, Lebanon and Cyprus, yet widespread violence did not occur there" (Hendrix, 2018, p.190).

- Scholars have "not focused more attention on those countries most likely to be affected by[/vulnerable to] climate change". For example, "comparatively climate-change exposed countries such as Bangladesh and Haiti have received very scant attention from researchers investigating climate-conflict impacts" (Hendrix et al., 2018, p.190).

- Scholars have "been focusing effort on cases where it is more convenient to conduct research" (Hendrix, 2018, p.190). For example, "Kenya, which ties as the single mostoften-mentioned country in the climate-conflict literature, is neither particularly conflictprone nor climate vulnerable" (Hendrix, 2018, p.191). 
Adams et al. (2018, p.200) conclude that "These biases mean that research on climate change and conflict primarily focuses on a few accessible regions, overstates the links between both phenomena and cannot explain peaceful outcomes from climate change". Hendrix (2018, p.191) argues that these findings have important implications (and limitations) for the understanding of "the socioeconomic and political conditions in which climate-related conflict is likely to emerge and for informing policy interventions designed to mitigate climate-conflict risk".

Gemenne et al. (2014) in their review of the robustness of present social sciences analysis in assessing the causes and consequences of climate change on human security, agree that the climate-security nexus is more complex than it appears and identify a number of areas where further research is needed. These include the need to analyse the absence of conflict in the face of climate risks, the need to expand the range of issues accounted for in analysis of climate and security including the impacts of mitigation response on domains of security, and the need to include theories of asymmetric power relations in explaining security dimensions (Gemenne et al., 2014, p.1).

\section{Climate-conflict links in Afghanistan}

As discussed above, climate-related conflict is highly context-specific. This review found that there is a major lack of robust studies and research into climate-conflict links in Afghanistan, despite its vulnerability to both climate change and conflict, reflecting the findings of Nordqvist and Krampe (2018).

Afghanistan is among the most vulnerable countries to the adverse impacts of climate change particularly in relation to drought and flooding (Thomas, 2016, p.i; see also Lukas and Rüttinger, 2016, pp.28-30 for a detailed contextual analysis of Afghanistan, including information on socioeconomic and political issues, conflict history and actors, illicit opium trade). This is in some part due to its level of exposure, but is also the consequence of very high sensitivity of its population to the stimulus of climate shocks (as calculated through socio-economic, cultural and political factors). Temperature is projected to increase more than the global average, with warming expected to reach between $1.7-2.3^{\circ} \mathrm{C}$ by 2050 depending on the emissions scenario used. Precipitation projections are much more uncertain but changes in the timing and volume of precipitation are expected and spring rainfall is expected to decrease over most of the country (NEPA, UNEP and WFP, 2016, pp.52-53). In general, droughts will become a norm by 2030 and flood events will be more intense. A study by NEPA, UNEP and WFP (2016, p.4) looked at the impact of climate change on livelihoods and food security in Afghanistan, focused on four climate hazards that "pose the largest risk to livelihoods in Afghanistan". These were: drought caused by reduced spring rain-fall, drought caused by declining river flows due to reduced spring-time snowmelt in the highlands, floods caused by increased heavy spring rainfall, and riverine floods caused by heavier and faster upstream snowmelt in the highlands. They predicted that future climate change would impact on these four areas. Women are among the most severely affected in Afghanistan as they are reliant on natural resources sensitive to changes in climate for their daily tasks, such as household water supply or collecting wood for cooking (Thomas, 2016, p.i).

Lukas and Rüttinger (2016) analysed the links between climate change and Non-State Armed Groups using four case studies that span the whole spectrum of Non-State Armed Groups and patterns of violence, conflict and fragility: Afghanistan, Guatemala, Lake Chad and Syria. Their Afghanistan case study emphasises the widely underreported and understudied issue of natural resources and their role in the conflicts, with competition over scarce resources partly driven by 
trying to gain political power through their control. Profit seeking interacts with other conflict drivers such as unresolved grievances, patronage, corruption, and a legacy of violence.

The authors stress that in Afghanistan:

"availability of water per capita is projected to decline by 50 percent by 2040 . Rising temperatures, increasing evapotranspiration and lower levels of rainfall, and weak infrastructure and water management systems will threaten the livelihoods of millions of rural Afghans, making them more vulnerable to illicit livelihoods and recruitment by armed groups. ...As climate change worsens conditions for rural farmers, support for [Non-State Armed Groups] is likely to increase as they enable farmers to access markets, provide capital for investment and thereby support economic development" (Lukas and Rüttinger, 2016, p.34).

Lukas and Rüttinger (2016, pp.31-34) highlight four major climate-fragility risks for Afghanistan in their literature review:

1) Land degradation and natural resource conflicts: Degradation and rapid population growth are increasing competition for land, which in turn feeds into long-standing ethnic conflicts between nomadic Pashtun pastoralists (Kuchi) and sedentary Hazara for access to pastures (Brown and Blankenship 2013 cited in Lukas and Rüttinger, 2016). According to experts, the conflict between the two groups is also driven by the Taliban, who provide arms to the Kuchi and use the conflict to win land from the foreign occupants and the national military and to secure trading routes for contraband goods.

2) Scarcity and illicit livelihoods: In Afghanistan, the agricultural sector contributes up to 28 percent of GDP, employs roughly 60 percent and underpins the livelihoods of 85 percent of the population (World Bank 2016a cited in Lukas and Rüttinger, 2016). However, only 12 percent of the total land is arable, and agriculture is mostly rain-fed, leaving it highly dependent on and vulnerable to erratic rainfall and winter snows in the Hindu Kush mountains. Water resources are not equitably distributed across Afghanistan. Water scarcity and livelihood insecurity drive farmers to engage in illicit poppy production instead of or in addition to alternative, more water-intensive crops such as wheat or almonds. Conflict and insecurity are also adversely affecting agricultural output. Reduced livelihood opportunities from drought can also make young people more vulnerable to recruitment by armed groups: during Afghanistan's 2006/07 drought, many young men in Balkh province opted to join the Taliban or other insurgent groups to diversify their livelihoods (Heijmans et al. 2009 cited in Lukas and Rüttinger, 2016).

3) Transboundary water conflicts and armed insurgency: Afghanistan is an upstream riparian country with four major rivers that are mainly fed by mountain streams. Regional cooperation is lacking and control of water sources has been used as an instrument of political provocation in the past. Climate change-related recurrent droughts and reduced river flow from earlier snow melt will likely increase pressure on scarce water resources. [Non-State Armed Groups], particularly the Taliban, are increasingly making use of the deep-seated regional tensions for their own strategic interests. According to a report published by the Environmental Law Institute and UNEP in 2014 (cited in Lukas and Rüttinger, 2016), Iran has adopted a paradoxical strategy of cooperation and destabilization in Afghanistan. On the one hand, it supports the development of efficient water use and transport systems and, on the other, it backs Taliban insurgent groups and direct actions against water diversions. 
4) Rapid-onset disasters and instability: Afghanistan is exposed to a variety of natural hazards. It was ranked 24th in the Global Climate Risk Index of countries most affected by extreme weather events over the past 20 years (1997-2016) (Eckstein et al., 2017, p.32). As glacier melt in Afghanistan's Hindu Kush mountains accelerates with climate change, rapid-onset disasters like flash floods, flooding and landslides are expected to increase (Kaltenborn et al. 2010 cited in Lukas and Rüttinger, 2016). Disaster preparedness is extremely low, as the country lacks effective early warning systems, and community resilience has been eroded by decades of conflict. As poverty and unemployment are among the mayor drivers of conflict in Afghanistan, inadequate and unequal disaster management can create a fertile ground for popular discontent or even violence (Government of Afghanistan 2011 cited in Lukas and Rüttinger, 2016).

Iqbal et al. (2018, p.1741) explored farmers' perceptions of drought prevalence, its socioeconomic impacts, their coping strategies, and types of conflicts and resolution mechanisms to it in Herat Province, Afghanistan. This was done using a questionnaire, which was completed by 147 farming households in August 2015. Their results showed that drought has had serious economic impacts, including loss of employment and reduction in crop yield and livestock production, which have reduced farmers' livelihood options and weakened their financial situation. Some of the social impacts have included migration, a sense of hopelessness and loss, conflicts over water, health problems, and limits to food options. The authors also highlighted that "Farmers used local techniques to adapt to drought and lessen its effects. Farmers perceived irrigation water to be a major source of conflict. Local elders, water-user associations, and formal courts were reported to be the most successful conflict resolution methods" (Iqbal et al., 2018, p.1741). The majority of the respondents said that the conflicts arise when some users fail to comply with the rotating water allocation and try to divert water illegally; approximately 26 percent of the respondents indicated that conflicts arise because of water scarcity, which intensifies during drought years (lqbal et al., 2018, p.1753).

In a working paper for the Swedish Expert Group for Aid Studies (EBA) developed from his Masters thesis, Bounadi (2018) constructed a new panel dataset on weather (precipitation and temperature) and conflicts across Afghanistan between July 2005 and December 2016. He finds that "exchanging colder for warmer days tends to increase the likelihood of conflict and that precipitation does not drive the occurrence of conflict" (Bounadi, 2018, p.5). Although he recognises that this is not always the case.

As part of the Secure Livelihoods Research Consortium (SLRC) publications, Huot and Pain (2017, p.6) report on the third wave of a longitudinal panel study tracing the livelihood trajectories of rural households in Afghanistan over a 14-year period in Sar-i-Pul province (one of three study sites). They report that cyclical drought periods in the province have led to a diversification of activities by households, including growing opium poppies. They also highlight that there is an assumption by the international community and Afghanistan government that agriculture is the main source of livelihoods for a majority of its population. The study concludes that there is:

"incoherence between the rhetoric of agricultural policy [in Afghanistan] and evidence on the ground..., rural households engage in a number of coping strategies to deal with both idiosyncratic shocks such as illnesses and marriage costs, as well as larger environmental crises, like droughts and floods. What is clear is that these coping strategies, while varied, are largely non-farm based; in almost no cases are households in a position to survive, let alone improve their circumstances, through agricultural pursuits alone...Thus, most households seek livelihood security from activities beyond the village, and therefore outside 
the rural economy, instead depending largely on remittance income and employment in urban sectors" (Huot and Pain, 2017, p.35).

\section{Other FCAS case studies ${ }^{1}$}

The following case studies offer examples from the literature of other regions and countries where a connection between climate change and conflict has attempted to be made. These vary in robustness and scale, and many of the conclusions drawn are contested. The findings are also very context specific. The above debate on the strength of the connections between climate change and conflict should also be kept in mind.

\section{East Africa and violent conflict}

van Baalen and Mobjörk (2018) explore how climate change affects the risk and dynamics of violent conflict. They emphasise that although there has been much research into climate-conflict risks and dynamics, less is known about the exact mechanisms through which climate change affects violent conflict. They undertook a systematic review of 43 peer-reviewed quantitative and qualitative articles published 1989-2016 on the relationship between climate-related change and local, violent conflicts in East Africa (van Baalen and Mobjörk, 2018, p.563). They show that conflicts around natural resources - land, pasture, water - are particularly frequent where livestock rearing pastoralists are involved. They identify four key mechanisms through their comprehensive analysis, which broadly reflect the four mechanisms identified by Nordqvist and Krampe (2018) in their review of climate-conflict studies for South Asia and South East Asia (see section 2). The four mechanisms identified by van Baalen and Mobjörk (2018, p.551) for how climate-related changes may lead to violent conflict in East Africa: i) deteriorating livelihoods, ii) increased migration and changes in pastoralist mobility patterns, iii) tactical considerations among armed groups, and iv) elite capture of local disaffection. They explain that "these explanations are often complimentary, intrinsically interlinked, and applicable to different stages of the chain from climate-related environmental change to violent conflict" (van Baalen and Mobjörk, 2018, p.551). These explanations for climate-conflict in East Africa also rely on different mechanisms, emphasise different actors, and focus on different types of outcomes, and so they also yield different expectations about when and where violence is most likely to occur (van Baalen and Mobjörk, 2018). There are also different political dynamics at play that condition or mediate the relationship. Van Baalen and Mobjörk (2018, p.564) emphasise the need for scholars to consider political, spatial and temporal dimensions when studying the links between environmental change and violent conflict, and recommend for these factors to be systematically included in calculations.

\section{Drought, migration and violence in Kenya}

Linke et al. (2018, p.1) used original national survey data from Kenya to investigate whether people who report relocating due to drought are more likely to be victims of violence than people who do not move. They also examine whether this migrant sample supports the use of violence at higher levels than the general population, conditional on their experiences. Controlling for many individual-level and contextual variables, they find that "those who have relocated are

\footnotetext{
${ }^{1}$ Another K4D helpdesk reviewed the evidence on climate change and stability in North Africa; see Price (2017) for further information and studies.
} 
consistently more likely to be victims of violence than those who have not, and that those who relocated temporarily support the use of violence at higher levels than the general population if, and only if, they are themselves victims of violence. Vulnerable migrant populations may be subject to violence as observational aggregate studies suggest, but they are not likely to be the sources of violence unless victimized first" (Linke et al., 2018, p.1). The authors recognise some limitations in their survey design and the influence of pastoral livelihoods in the sample.

\section{Livestock and drought in Somalia}

Maystadt and Ecker (2014, p.1157) explored a causal relationship between droughts and local violent conflict in Somalia, in a within-country setting over a short time frame. They estimated that a one standard deviation increase in drought intensity and length raised the likelihood of conflict by 62 percent. Furthermore, they found that "local livestock markets were the primary channel through which droughts fuel conflict in Somalia, and that livestock price downturns and hence losses in herders' income lower one's resistance to engage in conflict activities" (Maystadt and Ecker, 2014, p.1177).

\section{Hot-spot mapping in South and South East Asia}

Busby et al. (2018, p.88) recently attempted to hot-spot or map sub-national "climate security vulnerability" in 11 countries in South and Southeast Asia. They define climate security vulnerability as "areas where large numbers of people are at risk of death due to exposure to climate-related hazards and the follow-on consequences of exposure, including but not limited to conflict". The study used the Asian Climate Security Vulnerability Model Version 1 (ACSV V1) and found that "Bangladesh, parts of southern and western Myanmar (the Ayeyarwady region and Rakhine state), and parts of southern and northwest Pakistan (Sindh and Khyber Pakhtunkhwa provinces) were the most vulnerable from a climate security perspective" (Busby et al., 2018, p.88). The authors acknowledge the potential weaknesses and limitations of their model and the need for further iterations. However, they argue that their maps provide some insight of "underlying realities and are useful as a point of departure for deliberation and additional study", which are meant to "serve as preliminary focal points for discussion and research with country and regional experts" (Busby et al., 2018, p.102).

\section{Flooding in Pakistan}

A case study of flood mismanagement and fragility in Pakistan by Schilling et al. (2013) and summarised by Rüttinger et al. (2015, p.40), demonstrates how unprecedented flooding in 2010 and 2011 in the Sindh province resulting from extreme rainfall, exposed the region's poorly planned drainage and irrigation projects. This then exacerbated the human cost and environmental damages of the disaster. Rüttinger et al. (2015, p.40) argue that the "inadequacy of state responses in Sindh deepened existing grievances related to the marginalization of floodaffected communities and contributed to social unrest, small-scale protests, and demonstrations (Schilling et al. 2013)". Schilling et al. (2013) identified several ways in which environmental change contributes to existing conflicts in Pakistan, broadly classified into conflicts over land and over fish resources. They elaborated that "according to several farmers and other community members, the higher rainfall variability and frequency of floods as well as prolonged droughts have contributed to a decrease in vegetation cover and pasture... During the summer, people from the water deficient Thar area mostly come to Badin to graze their animals. ... Because of limited vegetation cover, the natives of Badin no longer allow Thari livestock to graze on their 
land. According to community respondents from Badin, these conflicts are affecting their income and weakening the status of the local communities" (Schilling et al., 2013, p.38).

\section{Drought and the Syrian conflict}

An example of a possible climate-conflict relationship that has received much attention is the contribution of a severe 3-year drought beginning in 2006/2007 as a major factor in the Syrian uprising in 2011. This is a controversial hypotheses, with literature both for (Kelley et al., 2015) and against (de Châtel, 2014) such a relationship. Kelley et al. (2015, P.1) argue, "For Syria, a country marked by poor governance and unsustainable agricultural and environmental policies, the drought had a catalytic effect, contributing to political unrest" and that this drought was linked with long-term climate change. They acknowledge the importance of other factors, and that their "analysis of the conflict in Syria shows an impact of an extreme climate event in the context of government failure, exacerbated by the singular circumstance of the large influx of Iraqi refugees" (Kelley et al., 2015, P.5).

However, this hypothesis is questioned as being simplistic and misleading by others. De Châtel (2014, p.532) argues instead that "The Syrian uprising that started in March 2011 was sparked by a series of inter-related social, economic and political factors", including decades of resource mismanagement, dysfunctional agricultural policies and a sudden removal of fuel subsidies and simultaneous dramatic increases in global food prices, under a repressive regime. She argues that although the drought may have exacerbated existing conditions, focusing on external factors like drought and climate change in the context of the Syrian uprising is counterproductive as it diverts attention from more fundamental political and economic motives behind the protests and shifts responsibility away from the Syrian government (De Châtel, 2014, p.532).

\section{Iraq climate-related security risk assessment}

A recent climate-related security risk assessment of Iraq undertaken by the Expert Working Group on Climate-related Security Risks emphasised that "[t]he combination of [Iraq's] hydrological limitations, increasing temperatures and extreme weather events puts pressure on basic resources and undermines livelihood security for Iraq's population" (Hassan et al., 2018, p.1). The report identified the following five priority climate-related security risks in Iraq amid this complex region (Hassan et al., 2018, pp.1-2):

1. Diminished agricultural livelihoods from increasing water scarcity increase local support for terrorist groups.

2. Insufficient governance capacity to address and respond to climate change and environmental degradation.

3. Increased dependence on water flows from riparian neighbours and regional stability as rainfall becomes more erratic in the region.

4. Mass displacement and forced migration due to the combination of increased rainfall variability and dam projects in neighbouring countries.

5. Heightened communal tensions over access to food and water due to erratic precipitation and increased temperatures from climate change leading to an intensified risk of more regular and prolonged periods of drought. 


\section{References}

Abrahams, D., \& Carr, E. R. (2017). Understanding the connections between climate change and conflict: contributions from geography and political ecology. Current Climate Change Reports, 3(4), 233-242. https://link.springer.com/article/10.1007/s40641-017-0080-z

Adams, C., Ide, T., Barnett, J., \& Detges, A. (2018). Sampling bias in climate-conflict research. Nature Climate Change, 8(3), 200. https://www.nature.com/articles/s41558-018-0068-2

Adger, W.N., Pulhin, J.M., Barnett, J., Dabelko, G.D., Hovelsrud, G.K., Levy, M., Oswald Spring, Ú. \& Vogel, C.H. (2014). Human security. In: Climate Change 2014: Impacts, Adaptation, and Vulnerability. Part A: Global and Sectoral Aspects. Contribution of Working Group II to the Fifth Assessment Report of the Intergovernmental Panel on Climate Change. [Field, C.B., Barros, V.R., Dokken, D.J., Mach, K.J., Mastrandrea, M.D., Bilir, T.E., Chatterjee, M., Ebi, K.L., Estrada, Y.O, Genova, R.C., Girma, B., Kissel, E.S., Levy, A.N., MacCracken, S., Mastrandrea, P.R. \& White, L.L. (eds.)]. Cambridge University Press, Cambridge, United Kingdom and New York, NY, USA, pp. 755-791. https://www.ipcc.ch/site/assets/uploads/2018/02/WGIIAR5-

Chap12_FINAL.pdf

Bounadi, M.E. (2018), Weather and Conflicts in Afghanistan, EBA Working Paper, June, 2018, Expert Group for Aid Studies, Sweden. https://eba.se/wpcontent/uploads/2018/06/WP_2018_06_Bounadi.pdf

Buhaug, H. (2015). Climate-conflict research: some reflections on the way forward. Wiley Interdisciplinary Reviews: Climate Change, 6(3), 269-275.

https://onlinelibrary.wiley.com/doi/full/10.1002/wcc.336

Burke, M., Hsiang, S.M., \& Miguel, E. (2015). "Climate and Conflict." Annual Review of Economics, 7(1): 577-617. https://www.annualreviews.org/doi/10.1146/annurev-economics080614-115430

Busby, J., Smith, T.G., Krishnan, N., Wight, C. \& Vallejo-Gutierrez, S. (2018). "In harm's way: Climate security vulnerability in Asia," World Development, Elsevier, vol. 112(C), pages 88-118. https://www.sciencedirect.com/science/article/pii/S0305750X18302365

Couttenier, M. \& Soubeyran, R. (2014). Drought and Civil War In Sub-Saharan Africa. Economic Journal, Royal Economic Society, vol. 124(575), pages 201-244, March.

De Châtel, F. (2014). The role of drought and climate change in the Syrian uprising: Untangling the triggers of the revolution. Middle Eastern Studies, 50(4), 521-535.

https://www.tandfonline.com/doi/abs/10.1080/00263206.2013.850076

Dell, M., Jones, B.F., \& Olken, B.A. (2014). What Do We Learn from the Weather? The New Climate-Economy Literature. Journal of Economic Literature, 52(3): 740-98.

https://scholar.harvard.edu/files/dell/files/learnfromweather.pdf

Eckstein, D., Künzel, V. \& Schäfer, L. (2017). Global Climate Risk Index 2018: Who Suffers Most From Extreme Weather Events? Weather-related Loss Events in 2016 and 1997 to 2016. Bonn: Germanwatch e.V.

https://www.germanwatch.org/sites/germanwatch.org/files/publication/20432.pdf 
Gemenne, F., Barnett, J., Adger, W.N., and Dabelko, G.D. (2014) 'Climate and Security: Evidence, Emerging Risks, and a New Agenda', Climatic Change, 123(1), 1-9.

https://link.springer.com/article/10.1007/s10584-014-1074-7

Hassan, K., Born, C. \& Nordqvist, P. (2018). Iraq: Climate-related security risk assessment. The Expert Working Group on Climate-related Security Risks, Stockholm International Peace Research Institute (SIPRI). https://www.eastwest.ngo/sites/default/files/iraq-climate-relatedsecurity-risk-assessment.pdf

Hendrix, C.S. (2018). Searching for climate-conflict links. Nature Climate Change, 8(3), 190. https://www.nature.com/articles/s41558-018-0083-3

Huot, D. \& Pain, A. (2017). Afghanistan livelihood trajectories: Life on the margins in Sar-i-Pul province. Working Paper 54. Secure Livelihoods Research Consortium. London: ODI. https://securelivelihoods.org/wp-content/uploads/14.-Afghanistan-livelihood-trajectories_life-onthe-margins-in-Sar-i-Pul-province.pdf

Iqbal, M. W., Donjadee, S., Kwanyuen, B., \& Liu, S. Y. (2018). Farmers' perceptions of and adaptations to drought in Herat Province, Afghanistan. Journal of Mountain Science, 15(8), 17411756. https://link.springer.com/article/10.1007/s11629-017-4750-z

Kelley, C. P., Mohtadi, S., Cane, M. A., Seager, R., \& Kushnir, Y. (2015). Climate change in the Fertile Crescent and implications of the recent Syrian drought. Proceedings of the National Academy of Sciences, 201421533.

https://www.pnas.org/content/early/2015/02/23/1421533112.short

Linke, A. M., Witmer, F. D. W., O'Loughlin, J., McCabe, J. T., \& Tir, J. (2018). The consequences of relocating in response to drought: human mobility and conflict in contemporary Kenya.

Environmental Research Letters, 13(9), 094014. http://iopscience.iop.org/article/10.1088/17489326/aad8cc/meta

Lukas, K., \& Rüttinger, L. (2016). Insurgency, Terrorism and Organised Crime in a Warming Climate: Analysing the Links Between Climate Change and Non-state Armed Groups. adelphi. https://www.adelphi.de/en/publication/insurgency-terrorism-and-organised-crime-warmingclimate

Maystadt, J. F., \& Ecker, O. (2014). Extreme weather and civil war: does drought fuel conflict in Somalia through livestock price shocks?. American Journal of Agricultural Economics, 96(4), 1157-1182. https://academic.oup.com/ajae/article/96/4/1157/2737500

NEPA, UNEP \& WFP (2016). (2016). Climate Change in Afghanistan: What Does it Mean for Rural Livelihoods and Food Security? National Environmental Protection Agency of Afghanistan (NEPA), United Nations Environment Programme (UNEP) and World Food Programme (WFP).

NEPA \& UNEP. (2015). Climate Change and Governance in Afghanistan. Kabul: National Environmental Protection Agency and United Nations Environment Programme.

https://wedocs.unep.org/bitstream/handle/20.500.11822/22447/Report_CC_Governance_Afghani stan_EN_v2.pdf?sequence=1\&isAllowed=y

Nordqvist, P. \& Krampe, F. (2018). Climate Change and Violent Conflict: Sparse Evidence from South Asia and South East Asia. SIPRI insights on peace and security no. 2018/4.

https://www.sipri.org/sites/default/files/2018-09/sipriinsight1804.pdf 
Price, R.A. (2017). Climate change and stability in North Africa. K4D Helpdesk Report 242. Brighton, UK: Institute of Development Studies.

https://assets.publishing.service.gov.uk/media/5a7052bded915d266017b8aa/242_Climate_chan ge_and_stability_in_Northern_Africa.pdf

Rüttinger, L., Stang, G., Smith, D., Taenzler, D. \& Vivekananda, J. et al. (2015). A New Climate for Peace: Taking Action on Climate and Fragility Risks. Berlin/London/ Washington/Paris: adelphi, International Alert, The Wilson Center, EUISS. https://www.newclimateforpeace.org/

Schilling, J., Vivekananda, J., Khan, M. A., \& Pandey, N. (2013). Vulnerability to environmental risks and effects on community resilience in mid-west Nepal and south-east Pakistan.

Environment and Natural Resources Research, 3(4), 27.

https://www.researchgate.net/profile/Janpeter_Schilling/publication/270586351_Vulnerability_to_ Environmental_Risks_and_Effects_on_Community_Resilience_in_Mid-West_Nepal_and_SouthEast_Pakistan/links/55debe5908aeaa26af0f2e6d/Vulnerability-to-Environmental-Risks-andEffects-on-Community-Resilience-in-Mid-West-Nepal-and-South-East-Pakistan.pdf

Schleussner, C. F., Donges, J. F., Donner, R. V., \& Schellnhuber, H. J. (2016). Armed-conflict risks enhanced by climate-related disasters in ethnically fractionalized countries. Proceedings of the National Academy of Sciences, 113(33), 9216-9221.

https://www.pnas.org/content/113/33/9216.short

Sida (The Swedish International Development Cooperation Agency). (2018). The relationship between climate change and violent conflict. Green tool box/Peace and security tool box:

Working paper, 2017. International Organisations and Policy Support, Sida.

https://www.sida.se/contentassets/c571800e01e448ac9dce2d097ba125a1/working-paper--climate-change-and-conflict.pdf

Stites, E. \& Bushby, K. (2017). Livelihood strategies and interventions in fragile and conflictaffected areas: Assessing trends and changes from 2012 to 2016. Secure Livelihoods Research Consortium, Working Paper 57. https://securelivelihoods.org/wp-content/uploads/7.-Livelihoodstrategies-and-interventions-in-fragile-and-conflict-affected-areas_-2012-to-2016.pdf

Thomas, V. (2016). Climate Change in Afghanistan: Perspectives and Opportunities. $1^{\text {st }}$ Edition. Kabul, Afghanistan: Heinrich Böll Stiftung - Afghanistan.

https://www.boell.de/sites/default/files/climate_change_in_afg_eng.pdf?dimension1=division_afg hanistan

van Baalen, S. \& Mobjörk, M. (2018). Climate Change and Violent Conflict in East Africa: Integrating Qualitative and Quantitative Research to Probe the Mechanisms, International Studies Review, 20(4), 547-575. https://doi.org/10.1093/isr/vix043

von Uexkull, N., Croicu, M., Fjelde, H., \& Buhaug, H. (2016). Civil conflict sensitivity to growingseason drought. Proceedings of the National Academy of Sciences, 113(44), 12391-12396. https://www.pnas.org/content/113/44/12391.short

Vivekananda, J., Schilling, J. \& Smith, D. (2014). Climate resilience in fragile and conflict-affected societies: concepts and approaches. Development in Practice, 24:4, 487-501. DOI:

$10.1080 / 09614524.2014 .909384$ 


\section{Acknowledgements}

We thank the following expert who voluntarily provided suggestions for relevant literature or other advice to the author to support the preparation of this report. The content of the report does not necessarily reflect the opinions of any of the experts consulted.

- Dr Florian Krampe, Stockholm International Peace Research Institute (SIPRI)

\section{Suggested citation}

Price, R.A. (2019). Climate change as a driver of conflict in Afghanistan and other Fragile and Conflict Affected States. K4D Helpdesk Report 527. Brighton, UK: Institute of Development Studies.

\section{About this report}

This report is based on six days of desk-based research. The K4D research helpdesk provides rapid syntheses of a selection of recent relevant literature and international expert thinking in response to specific questions relating to international development. For any enquiries, contact helpdesk@k4d.info.

K4D services are provided by a consortium of leading organisations working in international development, led by the Institute of Development Studies (IDS), with Education Development Trust, Itad, University of Leeds Nuffield Centre for International Health and Development, Liverpool School of Tropical Medicine (LSTM), University of Birmingham International Development Department (IDD) and the University of Manchester Humanitarian and Conflict Response Institute (HCRI).

This report was prepared for the UK Government's Department for International Development (DFID) and its partners in support of pro-poor programmes. It is licensed for non-commercial purposes only. K4D cannot be held responsible for errors or any consequences arising from the use of information contained in this report. Any views and opinions expressed do not necessarily reflect those of DFID, K4D or any other contributing organisation. (C) DFID - Crown copyright 2019.

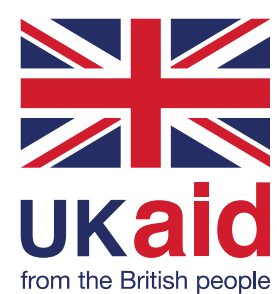

